\title{
Production of Esterified Nanofibrillated Cellulose from a Lesser-known Wood Species (Macaranga hypoleuca)
}

\author{
Eko Sutrisno, ${ }^{\text {a }}$ Supachok Tanpichai, ${ }^{\text {b,c }}$ and Surawut Chuangchote ${ }^{\mathrm{d}, \mathrm{e}, *}$ \\ Macaranga hypoleuca, a lesser-known and rarely used wood species, is a \\ pioneer species in the secondary succession that is classified as a fast- \\ growing plant with long fibers. $M$. hypoleuca was composed of \\ holocellulose, lignin, and extractives, at contents of $68.1 \pm 0.5 \%, 25.5 \pm$ \\ $0.6 \%$, and $4.7 \pm 0.1 \%$, respectively. In this study, refined $M$. hypoleuca pulp \\ was treated by alkali treatment, delignification, and maleic acid hydrolysis. \\ The pre-treated pulp was further disintegrated by mechanical treatment, \\ which produced nanofibrillated cellulose (NFC) with a yield of $53.5 \pm 2.7 \%$. \\ The average diameter of the NFC was $43.0 \pm 4.9 \mathrm{~nm}$. The use of maleic \\ acid $\left(\mathrm{C}_{4} \mathrm{H}_{4} \mathrm{O}_{4}\right)$ hydrolysis also reduced the hydrophilicity of the NFC, as \\ confirmed by the Fourier-transform infrared (FTIR) spectra. It was \\ determined that the Macaranga tree is a suitable lignocellulose source to \\ produce NFC, which can be used in transparent flexible substrates, \\ coating, and composite applications.
}

DOI: 10.15376/biores.17.1. 922-938

Keywords: Nanofibrillated cellulose; Macaranga hypoleuca; Fabrication; Chemical compounds; Pulp

Contact information: a: Nanoscience and Nanotechnology Graduate Program, King Mongkut's University of Technology Thonburi (KMUTT), 126 Prachauthit Rd., Bangmod, Thungkru, Bangkok 10140, Thailand; b: Learning Institute, King Mongkut's University of Technology Thonburi (KMUTT), 126 Prachauthit Rd., Bangmod, Thungkru, Bangkok 10140, Thailand; c: Cellulose and Bio-based Nanomaterials Research Group, King Mongkut's University of Technology Thonburi (KMUTT), 126 Prachauthit Rd., Bangmod, Thungkru, Bangkok 10140, Thailand; d: Department of Tool and Materials Engineering, Faculty of Engineering, King Mongkut's University of Technology Thonburi (KMUTT), 126 Prachauthit Rd., Bangmod, Thungkru, Bangkok 10140, Thailand; and e: Research Center of Advanced Materials for Energy and Environmental Technology (MEET), King Mongkut's University of Technology Thonburi (KMUTT), 126 Prachauthit Rd., Bangmod, Thungkru, Bangkok 10140, Thailand.

* Corresponding author: surawut.chu@ kmutt.ac.th

\section{INTRODUCTION}

Macaranga hypoleuca is a natural resource that is easily found in secondary successions. M. hypoleuca is a fast-growing species that is widely distributed in Southeast Asia, especially in Indonesia, Malaysia, Singapore, and Thailand (Slik and Van Welzen 2001). Compared to other fast-growing tree species such as Cratoxylon arborescens, Terminalia microcarpa, Artocarpus hispidus, and Ochroma pyramidae, the Macaranga species has the fastest growth rate (Romàn-Dañobeytia et al. 2015; Yamada et al. 2016; Lampela et al. 2017; Junaedi 2018). The Macaranga species grow in height and diameter at an average annual rate of $2.3 \mathrm{~m}$ and $2.6 \mathrm{~cm}$, respectively (Junaedi 2018). Furthermore, Macaranga pulp is capable of producing fibers with a yield, fiber length, and diameter of 45.4\%, 1.4 to $1.7 \mathrm{~mm}$, and 24.5 to $29.8 \mu \mathrm{m}$, respectively (Frianto and Rinanda 2015; Takeuchi et al. 2016). These properties present $M$. hypoleuca as a potential source to prepare nanofibrillated cellulose (NFC). 
NFC has attracted great interest because of its superior characteristics such as strength, thermal expansion, and degradability (Kargarzadeh et al. 2018; Tanpichai et al. 2019; Tanpichai et al. 2019; Meng et al. 2020; Tanpichai et al. 2020). It has been widely reported that NFC is suitable in the manufacturing of nanocomposites, coatings, food packaging materials, conductive inks, and printed electronic devices (Koga et al. 2013; Wang et al. 2013; Nogi et al. 2015; Guo et al. 2016; Biswas et al. 2019). In general, chemical and mechanical treatments are used to purify and extract NFC (Tanpichai and Witayakran 2016; Petroudy et al. 2017; Tanpichai and Witayakran 2017; Trache et al. 2017; Wang et al. 2018; Yue and Qian 2018). Pelissari et al. (2014) reported that chemical treatment alone was not able to disintegrate NFC from microfibrils. Therefore, the defibrillation process is required to fibrillate NFC from the bounded microfibrils after the typical chemical treatment (Chen et al. 2011a; Tonoli et al. 2012; Zhao et al. 2013). During the chemical treatment, acid penetrates the plant cell walls and attacks the amorphous parts. The solvent concentration and the reaction time used during the acid hydrolysis depends on the type of materials used (Pelissari et al. 2014; Khawas and Deka 2016). Sulfuric acid $\left(\mathrm{H}_{2} \mathrm{SO}_{4}\right)$, classified as a non-environmentally friendly and corrosive chemical, can contaminate the cellulose nanomaterials and cause difficulties in functionalization due to the presence of the sulfate groups (Chen et al. 2016). In addition, the presence of active sulfate groups on the fiber surface leads to low thermal stability of the cellulose (Chen et al. 2017). Thus, an alternative acid for hydrolysis process may be more suitable for the production of NFC.

Maleic acid $\left(\mathrm{C}_{4} \mathrm{H}_{4} \mathrm{O}_{4}\right)$, a type of dicarboxylic acid, is a capable acid that is used in the acid hydrolysis process. At ambient temperature, $\mathrm{C}_{4} \mathrm{H}_{4} \mathrm{O}_{4}$ has low water solubility, so it can be crystallized. This results in a low recovery cost via crystallization (Chen et al. 2016). The optimum concentration of $\mathrm{C}_{4} \mathrm{H}_{4} \mathrm{O}_{4}$ can degrade hemicellulose and depolymerize cellulose (Bian et al. 2017a). Moreover, due to the hydrophilicity of NFC, it is difficult for NFC to fully disperse in hydrophobic polymers. Most commodity plastics are made up of hydrophobic polymers such as polyethylene, polypropylene, or natural rubber. In order to improve the dispersion of NFC in hydrophobic polymers, a coupling agent or cellulose functionalization is required. Kargarzadeh et al. (2017) reported that the grafting of long molecular chains on the NFC surface enhanced the dispersibility of NFC in a hydrophobic matrix due to the steric barrier and interparticle distances. In addition, $\mathrm{C}_{4} \mathrm{H}_{4} \mathrm{O}_{4}$ is environmentally friendly and can be used several times. Herein, $\mathrm{C}_{4} \mathrm{H}_{4} \mathrm{O}_{4}$ was used for acid hydrolysis to functionalize NFC extracted from a fast-growing wood species, $M$. hypoleuca. The steps of the popular NFC fabrication were improved. In the pre-treatment phase, base-acid agents were employed to eliminate hemicellulose and lignin. By such means, it was possible to remove the lignin with just one treatment while other researchers have used repeated bleaching treatments ( 4 to 5 times). Furthermore, this work provides an alternative potential hydrolysis process using the weak acid for NFC fabrication.

\section{EXPERIMENTAL}

\section{Materials}

The M. hypoleuca pulp (Reichb.f. \& Zoll., Müll. Arg.), the raw material for the NFC production, was obtained from the Research and Development of Forest Fiber Technology Institute of the Ministry of Environment and Forestry of the Republic of Indonesia ( $2 \mathrm{~g}$ with $10.37 \%$ of water content). The potassium hydroxide $(\mathrm{KOH})$ and the sodium hydroxide $(\mathrm{NaOH})$ were obtained from Carlo Erba Reagents (Barcelona, Spain). 
The sodium chlorite $\left(\mathrm{NaClO}_{2}\right)$ and the hydrochloric acid were obtained from Ajax Finechem Pty, Ltd. (New South Wales, Australia). Maleic acid $\left(\mathrm{C}_{4} \mathrm{H}_{4} \mathrm{O}_{4}\right)$ was obtained from Merck KGaA (Darmstadt, Germany), and acetic acid $\left(\mathrm{CH}_{3} \mathrm{COOH}\right)$ was obtained from RCI Labscan (Bangkok, Thailand). All of the chemicals were analytical grade.

\section{Pre-treatment of the Pulp}

The dried $M$. hypoleuca pulp ( $1 \mathrm{~g}$ ) was immersed in $50 \mathrm{~mL}$ of $10 \% \mathrm{w} / \mathrm{v} \mathrm{KOH}$ solution under continuous stirring at room temperature for $14 \mathrm{~h}$. The treated pulp was washed several times with distilled water until the $\mathrm{pH}$ became neutral. The pulp was then bleached once with a $10 \%$ w/v acidified $\mathrm{NaClO}_{2}$ solution at $70{ }^{\circ} \mathrm{C}$ for $2 \mathrm{~h}$. After that, the pulp was treated with $30 \% \mathrm{w} / \mathrm{v} \mathrm{NaOH}$ solution at $170{ }^{\circ} \mathrm{C}$ for $1.5 \mathrm{~h}$. Finally, the pulp was washed with distilled water until the $\mathrm{pH}$ reached a neutral level. The pre-treated pulp was kept in the wet condition until further use.

\section{Preparation of the NFC}

The chemical and mechanical treatments were used to produce the NFC from the $M$. hypoleuca pulp. The pre-treated pulp was first hydrolyzed using an $80 \% \mathrm{w} / \mathrm{v} \mathrm{C}_{4} \mathrm{H}_{4} \mathrm{O}_{4}$ solution at $120{ }^{\circ} \mathrm{C}$ for $4 \mathrm{~h}$. The pulp was separated from the solution using centrifugation at $10,000 \mathrm{rpm}$ for $20 \mathrm{~min}$, and neutralized in a dialysis bag with distilled water. Subsequently, the treated pulp in the pre-treatment phase (with a yield of $67.8 \pm 0.1 \%$ ) was added into $120 \mathrm{~mL}$ deionized water before mechanical treatment, and the temperature was kept at less than $10^{\circ} \mathrm{C}$. It was disintegrated with an ultrasonication processor (Cole Parmer, Vernon Hills, IL, United States) for $30 \mathrm{~min}$ at an output power of 2,000 W. Finally, the NFC suspension was stored in a refrigerator at a temperature of $5{ }^{\circ} \mathrm{C}$. Figure 1 shows the pre-treatment steps and the NFC preparation process which were adopted from Pelissari et al. (2014) with modifications. The formulation of the modified schemes was based on the preliminary data of this study.

\section{Characterizations of the NFC}

Chemical composition of the pulp

The contents of the cellulose, hemicellulose, and lignin were analyzed according to the standards of the Technical Association of the Pulp and Paper Industry (TAPPI). Briefly, an extractive-free pulp sample of 0.5 to $1 \mathrm{~g}$ was hydrolyzed with $3 \mathrm{~mL}$ of $72 \% \mathrm{H}_{2} \mathrm{SO}_{4}$ at $30{ }^{\circ} \mathrm{C}$ for $1 \mathrm{~h}$. The suspension was diluted to $4 \%$ and autoclaved for $1 \mathrm{~h}$ at $120{ }^{\circ} \mathrm{C}$. The remained material was filtered as insoluble lignin, according to the TAPPI standard T222 om-11 (2015). The holocellulose content was determined according to the TAPPI standard T9 wd-75 (2015). The extraction process was done in accordance with the TAPPI standard T280 wd-06 (2015). The extractive-free pulp sample (1 to $2 \mathrm{~g}$ ) was dispersed in $5 \mathrm{~mL}$ of deionized water. Then, $2 \mathrm{~mL}$ of $\mathrm{CH}_{3} \mathrm{COOH}$ and $5 \mathrm{~mL}$ of $80 \% \mathrm{NaClO}_{2}$ were added to the suspension. The suspension was soaked in a $90{ }^{\circ} \mathrm{C}$ water bath for $1 \mathrm{~h}$. After that, $4 \mathrm{~mL}$ of $\mathrm{CH}_{3} \mathrm{COOH}$ and $10 \mathrm{~mL}$ of $80 \% \mathrm{NaClO}_{2}$ were added to the solution and the reaction continued for $1 \mathrm{~h}$ at $90{ }^{\circ} \mathrm{C}$. The insoluble material was washed with deionized water, filtered and dried at $105{ }^{\circ} \mathrm{C}$. The remaining material was the holocellulose. Furthermore, the holocellulose $(0.5$ to $1 \mathrm{~g}$ ) was treated with $8 \mathrm{~mL}$ of $17.5 \% \mathrm{NaOH}$ for $30 \mathrm{~min}$ at room temperature. Subsequently, $8 \mathrm{~mL}$ of deionized water was added to the suspension and the reaction continued for another $30 \mathrm{~min}$. The solid material from this process was washed and soaked in $20 \mathrm{~mL}$ of $1.0 \mathrm{M} \mathrm{CH}_{3} \mathrm{COOH}$ for $5 \mathrm{~min}$. The solid material residue was alphacellulose. 


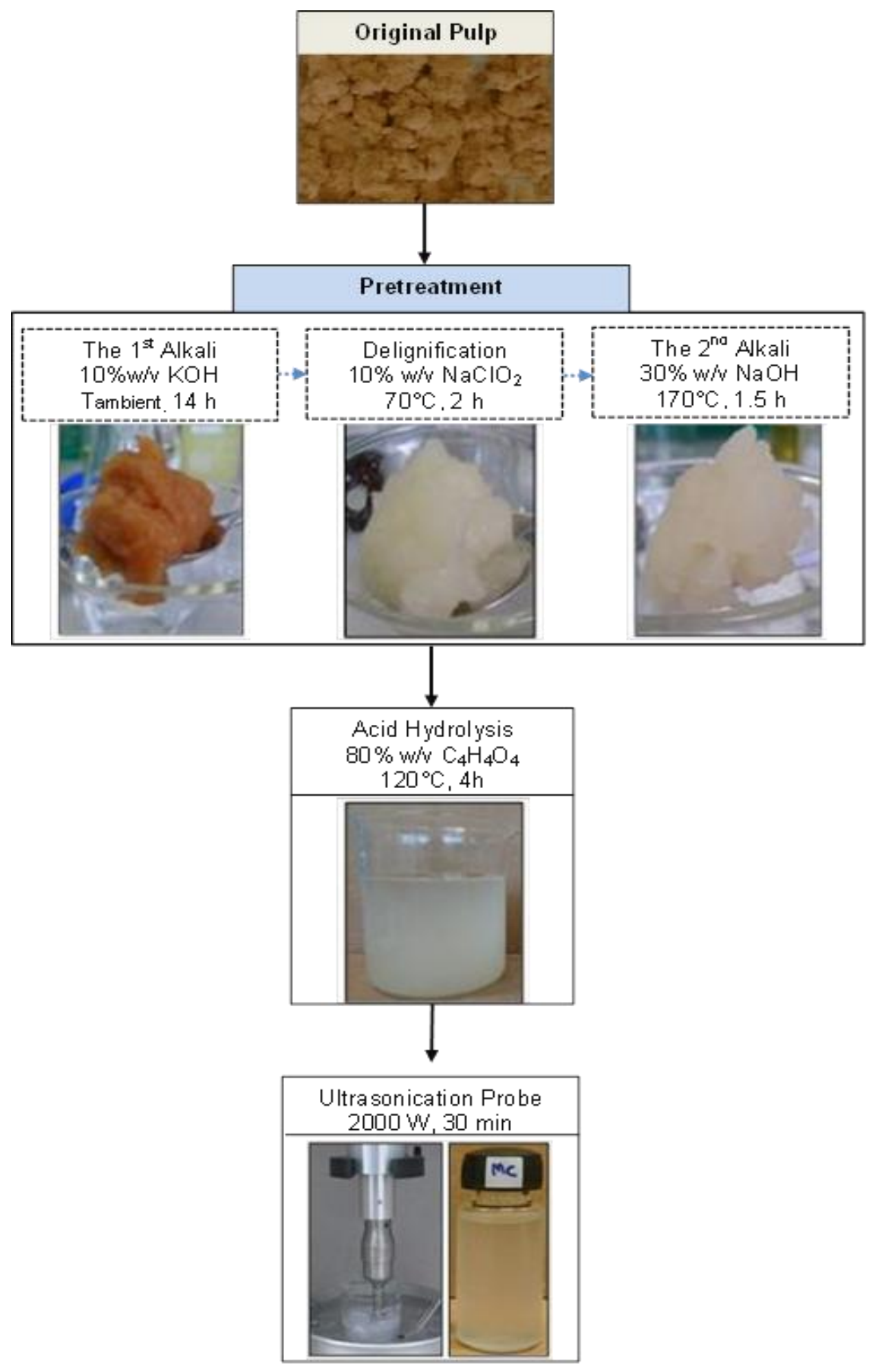

Fig. 1. Schematic illustration of the pre-treatment and the NFC preparation

\section{NFC yield}

The NFC yield was calculated by the difference in the weight of the dried original pulp and the weight of the dried NFC, as seen in Eq. 1, 


$$
\text { Yield }(\%)=\frac{\mathrm{NFC} \text { weight }(\mathrm{g})}{\text { Samples weight }(\mathrm{g})} \times 100
$$

Scanning electron microscopy

The morphology of the original pulp and NFC were investigated using a JSM-6610LV scanning electron microscope (SEM) (JEOL Ltd., Tokyo, Japan). A diluted cellulose suspension was dropped on a stub and dried in an oven at $50{ }^{\circ} \mathrm{C}$ for $3 \mathrm{~h}$. Before the measurement, the sample was coated with a thin layer of gold to enhance the conductivity. These SEM images were used to measure the average diameters of NFC using Image-J software. Each zone of NFC was measured with 10 replications. Data of diameters from the five zones were calculated to get the average and distribution of NFC diameters.

\section{$X$-ray diffraction}

The freeze-dried samples were subjected to a reflection mode of the X-ray diffraction (XRD) measurement. The XRD patterns were obtained by a D8 DISCOVER diffractometer (Bruker, Billerica, MA) with $\mathrm{CuK} \alpha$ radiation (40 kV and $40 \mathrm{~mA}$ ). The diffraction data of the cellulose samples were collected with an angular $2 \theta$ range from 2 to $50^{\circ}$, with a scanning speed of $1.2^{\circ} / \mathrm{min}$. The crystallinity index $(\mathrm{CI})$ of the samples was estimated from the diffraction intensity (Segal et al. 1959) using Eq. 2,

$$
C I=\frac{I_{200}-I_{a m}}{I_{200}} \times 100
$$

where $I_{200}$ is the maximum intensity of the (200) lattice diffraction and $I_{a m}$ is the intensity diffraction of the amorphous region.

Fourier-transform infrared spectroscopy analysis

Fourier-transform infrared (FTIR) spectra of the cellulose samples were recorded by a Nicolet 6700 Spectrometer (Thermo Fisher Scientific, Waltham, MA). The analysis was performed in the infrared region within a range of 600 to $4000 \mathrm{~cm}^{-1}$.

\section{Thermogravimetric analysis}

The thermogravimetric analysis (TGA) of the intact pulp and the NFC were investigated using a TGA/DSC 1 Stare system (Mettler Toledo, Columbus, OH). The dried samples were heated from 25 to $800{ }^{\circ} \mathrm{C}$ at a heating rate of $10{ }^{\circ} \mathrm{C} / \mathrm{min}$ under a nitrogen atmosphere at a flow rate of $100 \mathrm{~mL} / \mathrm{min}$.

\section{RESULTS AND DISCUSSION}

\section{Chemical Composition of the Pulp and NFC}

The chemical compositions of the M. hypoleuca pulp and other pulps from the Macaranga genus are presented in Table 1. The M. hypoleuca pulp suitable for the NFC fabrication, compared to the other pulps from the Macaranga family because the $M$. hypoleuca pulp has a lower content of lignin. Therefore, fewer amounts of chemicals and energy are required for the preparation of NFC, since lignin acts as a glue to adhere the nanofibrils together. 
Table 1. Chemical Compositions of the Pulps from the Macaranga genus

\begin{tabular}{|l|c|c|c|c|c|c|}
\hline \multirow{2}{*}{$\begin{array}{l}\text { Lignocellulose } \\
\text { Source }\end{array}$} & \multicolumn{5}{|c|}{ Chemical Composition (\%) } & \multirow{2}{*}{ Reference } \\
\cline { 2 - 6 } & Holocellulose & $\begin{array}{c}\text { Alpha- } \\
\text { cellulose }\end{array}$ & Hemicellulose* & Lignin & Extractive & n/a \\
\hline $\begin{array}{l}\text { Macaranga } \\
\text { gigantea }\end{array}$ & 55.14 & $\mathrm{n} / \mathrm{a}$ & $\mathrm{n} / \mathrm{a}$ & 35.97 & $\begin{array}{c}\text { Frianto and } \\
\text { Rinada } \\
(2015)\end{array}$ \\
\hline $\begin{array}{l}\text { Macaranga } \\
\text { bancana }\end{array}$ & $\mathrm{n} / \mathrm{a}$ & $\mathrm{n} / \mathrm{a}$ & $\mathrm{n} / \mathrm{a}$ & 27.20 & $\mathrm{n} / \mathrm{a}$ & $\begin{array}{c}\text { Takeuchi } \text { et al. } \\
\text { (2016) }\end{array}$ \\
\hline $\begin{array}{l}\text { Macaranga } \\
\text { pearsonii }\end{array}$ & $\mathrm{n} / \mathrm{a}$ & $\mathrm{n} / \mathrm{a}$ & $\mathrm{n} / \mathrm{a}$ & 28.00 & $\mathrm{n} / \mathrm{a}$ & \\
\hline $\begin{array}{l}\text { Macaranga } \\
\text { hypoleuca }\end{array}$ & $68.1 \pm 0.5$ & $65.6 \pm 0.1$ & $2.5 \pm 0.6$ & $25.5 \pm 0.6$ & $4.7 \pm 0.1$ & This work \\
\hline
\end{tabular}

*The hemicellulose content was calculated by subtracting the alphacellulose content from the holocellulose content (Cruz et al. 2018)

Pre-treatment is generally used to eliminate the non-cellulosic components (hemicellulose, lignin, and extractive substances), and increase the purity of the cellulose content. For the selection of pre-treatment chemicals, it is important to consider the ability of the chemical to penetrate the vessels of the wood tissue (Wang et al. 2018). In this work, $\mathrm{KOH}, \mathrm{NaClO}_{2}$, and $\mathrm{NaOH}$ were the chemicals used in the pre-treatment steps. After pretreatment, the fiber yield was $67.8 \pm 0.1 \%$.

The acid hydrolysis of the pre-treated pulp was further carried out using $\mathrm{C}_{4} \mathrm{H}_{4} \mathrm{O}_{4}$ solution. After the chemical and mechanical treatments, the yield of the NFC extracted from $M$. hypoleuca was reduced to $53.5 \pm 2.7 \%$ which was higher than that of NFC derived from poplar wood (32\%) (Yue and Qian 2018).

\section{Morphology of Pulp and NFC}

The structure of the $M$. hypoleuca pulp as a lignocellulosic resource was altered after each chemical treatment. The effect of each treatment on the chemical phase is shown by the red arrows in Figs. 2(b) through 2(d). The size of the raw materials decreased after the pre-treatment to purify the matter from lignin and hemicellulose. Higher amounts of disintegrated microfibrils were observed due to the elimination of the non-cellulosic components.

Lastly, the NFC obtained from the mechanical treatment is shown in Figs. 2(e) and 2(f). The diameter contribution of the NFC produced from the M. hypoleuca pulp hydrolyzed by $\mathrm{C}_{4} \mathrm{H}_{4} \mathrm{O}_{4}$ was in the range of 8 to $62 \mathrm{~nm}$ with the median of $43.0 \pm 8.5 \mathrm{~nm}$, as shown in Fig. 3. 


\section{bioresources.com}
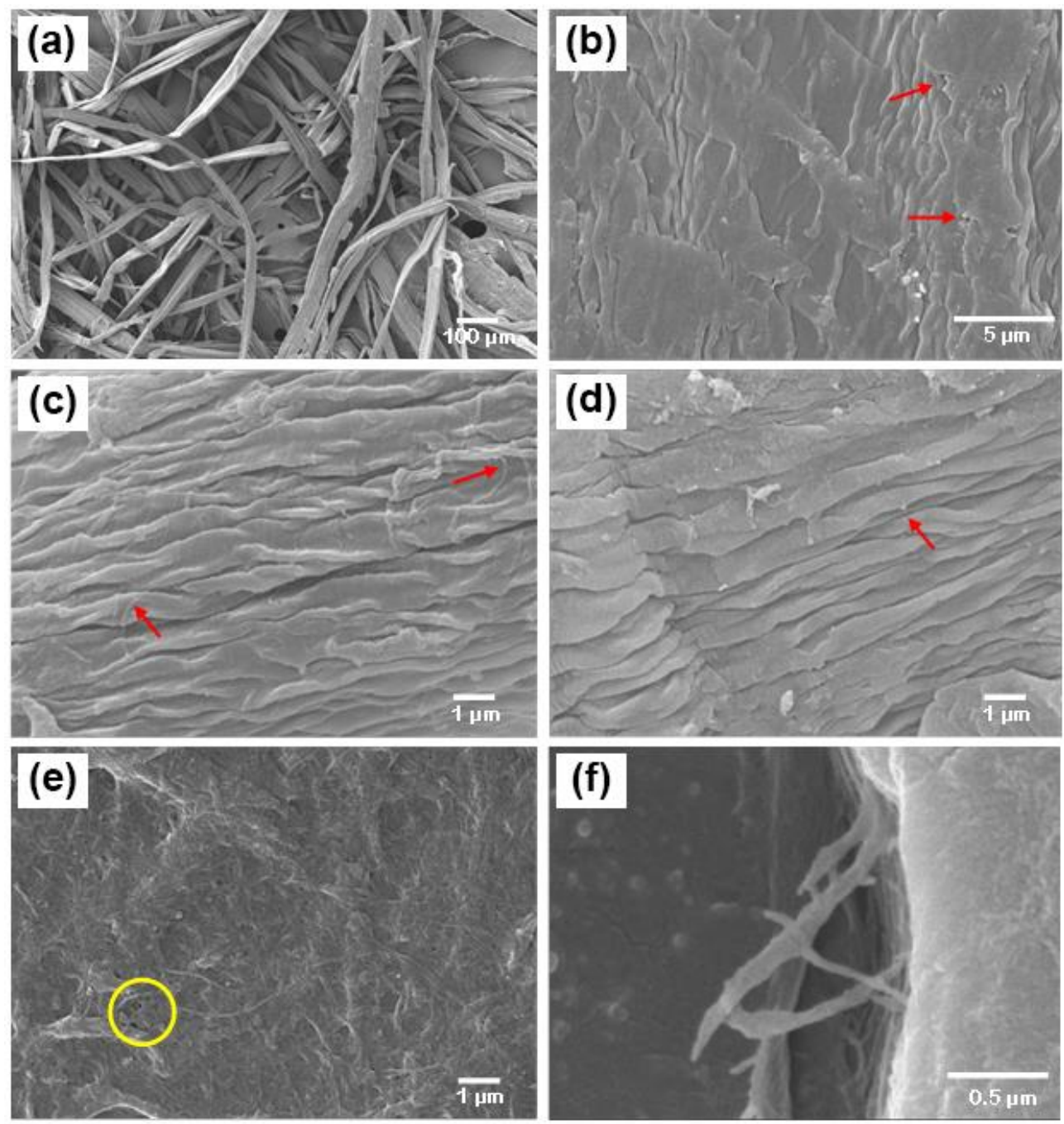

Fig. 2. Scanning electrom microscopy (SEM) images of the M. hypoleuca pulp that was subjected to (a) no treatment, (b) pre-treatment, (c) alkali treatment, (d) acid hydrolysis, and (e,f) ultrasonication 


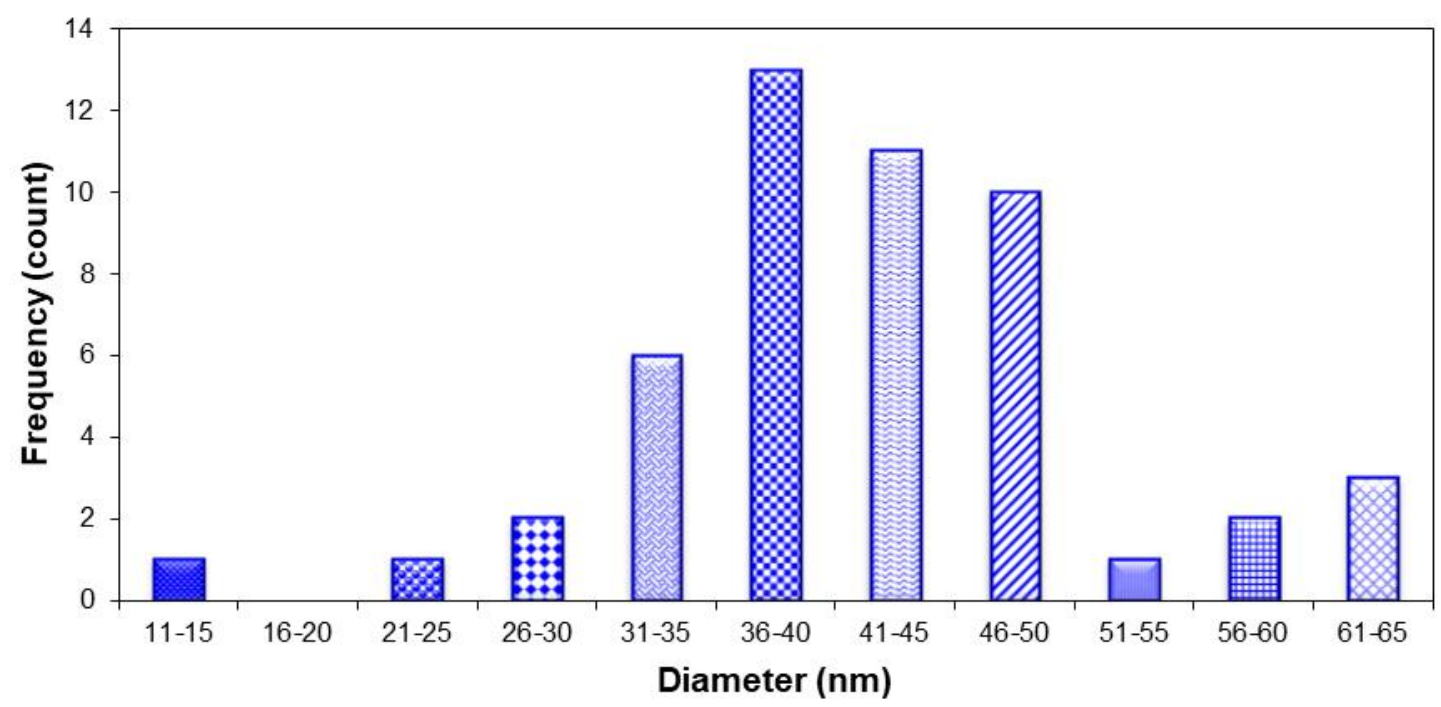

Fig. 3. Distribution of the diameters of NFC made from the Macaranga pulp

\section{XRD Analysis}

Figure 4 shows the XRD patterns of the untreated pulp, the treated pulp, and NFC. The NFC and untreated pulp had different patterns. The crystallinity of the NFC was observed at $2 \theta$ of $11.88^{\circ}(1-10), 19.88^{\circ}(110)$, and $21.74^{\circ}(200)$. The shift of these cellulose peaks indicated the changes of the crystal type from type I to type II (French 2014). This transformation was caused by the alkali treatment (Li et al. 2014). The CI of NFC was $78.4 \%$ which was higher than that of the M. hypoleuca pulp (64.1\%). The increased CI was attributed to the reduction in the amorphous region. The fluctuation of crystallinity index is related to intramolecular and intermolecular hydrogen bonds, whereas the alkaline treatment process affected the extent of hydrogen bonds within the cellulose, as well as changing the morphological structure (Ciolacu et al. 2011). Moreover, the reduction of CI in the NFC has been reported to depend on the power setting of the ultrasonication probe used for mechanical treatment, and/or high concentration of chemical solvents which destroyed the amorphous zone (Chen et al. 2011b). It was noted that the CI of the NFC extracted from M. hypoleuca was higher than that of the Pinus (43.4\%) and Eucalyptus (49.3\%) (Poletto et al. 2014). The variation of the cellulosic material types and fabrication conditions (e.g. the concentration of the chemical liquid, the reaction time, and the temperature) could play a vital role in this case. The increased CI has been correlated to a higher Young's modulus value through the schemes of transfer crystal energy (Ratanaphan et al. 2015). Therefore, the NFC prepared in this work could be suitable as a reinforcing material in composites (Phiriyawirut and Maniaw 2012; Yue and Qian 2018). 


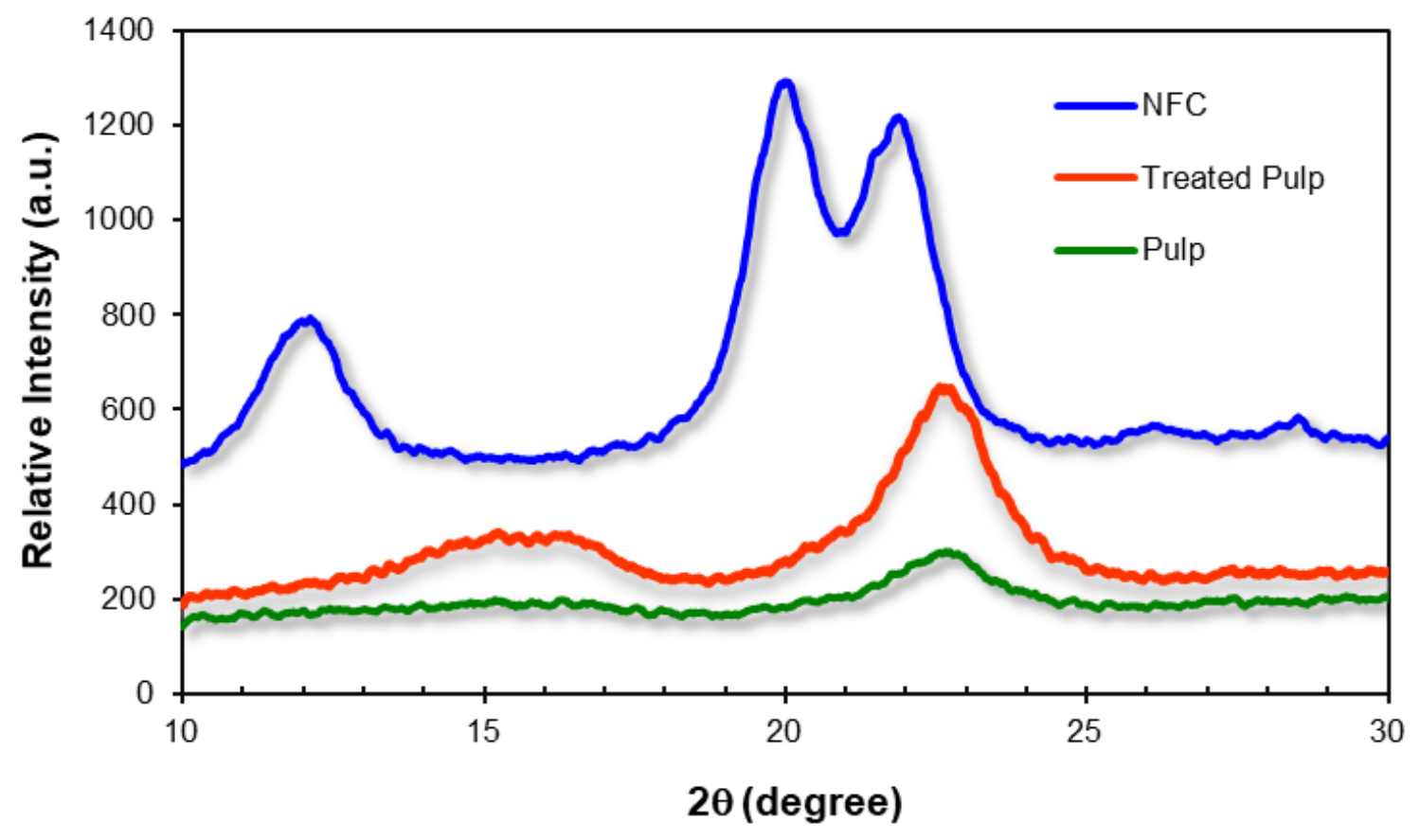

Fig. 4. X-ray diffraction (XRD) patterns of the M. hypoleuca pulp, treated pulp, and NFC

\section{FTIR Analysis}

FTIR was used to investigate changes in chemical structures obtained after the esterification process. The FTIR spectra of the original M. hypoleuca pulp and NFC are shown in Fig. 5(a) The peak shift, corresponding to the O-H stretching vibration in cellulose (Oh et al. 2005; Poletto et al. 2014), was seen from the $3340 \mathrm{~cm}^{-1}$ peak of the pulp to the $3443 \mathrm{~cm}^{-1}$ peak of the NFC. This shift was due to cellulose transformation from type I to type II and the loss of the non-cellulosic components (Wang et al. 2018).

The peak at $2898 \mathrm{~cm}^{-1}$ is assigned to the $\mathrm{C}-\mathrm{H}$ stretching vibrations from the cellulose molecules, hemicellulose, and lignin (Pacheco et al. 2018; Tanpichai, Witayakran, and Boonmahitthisud 2019). The peak at $1591 \mathrm{~cm}^{-1}$ observed from the pulp represents the aromatic ring vibration and the $\mathrm{C}-\mathrm{H}$ deformation vibration of the lignin from the wood fibers (Chen et al. 2011b), while this peak disappeared from the NFC spectrum due to the removal of the lignin (Tibolla et al. 2018). The difference in the sharpness of the existing peak indicates the quantity of the wood chemical compounds which were affected by the fabrication process. From all the peaks, it can be implied that the NFC produced from the softwood pulp still contained lignin and hemicellulose. The peaks located at 1162 and $1022 \mathrm{~cm}^{-1}$ corresponding to C-O-C symmetric stretching in cellulose were observed for both cellulose pulp and NFC (Tibolla et al. 2018).

The presence of the carboxylate groups within NFC introduced by the esterification with the $\mathrm{C}_{4} \mathrm{H}_{4} \mathrm{O}_{4}$ could be confirmed by the peak located at $1722 \mathrm{~cm}^{-1}$, corresponding to the $\mathrm{C}=\mathrm{O}$ vibration in the carbonyl groups (Bian et al. 2017b). The presence of ester bonding was attributed to the transformation of the hydroxyl (-OH) groups to carboxylic groups (COOH) (Chen et al. 2016), as shown in Fig. 5(b). The carboxyl content could affect the surface charges of NFC as well as its dispersion in a solvent. The carboxyl content of NFC determined using titration was found to be $0.33 \mathrm{mmol} / \mathrm{g}$. Also, according to visual observation, the result of NFC was comparable to eucalyptus pulp hydrolyzed by maleic 
acid with the carboxyl content of 0.05 to $0.15 \mathrm{mmol} / \mathrm{g}$ (Bian et al. 2017) and eucalyptus pulp hydrolyzed with oxalate acid with the carboxyl content of $0.39 \mathrm{mmol} / \mathrm{g}$ (Chen et al. 2016). Additionally, the carboxylation transformation could result in less hydrophilic properties for cellulose (Sethi et al. 2018).

\section{Thermal Properties}

The degradation of the hemicellulose and cellulose has been found at approximately 300 and $350{ }^{\circ} \mathrm{C}$ while lignin degraded between 250 and $600{ }^{\circ} \mathrm{C}$, respectively (Poletto et al. 2014). The TGA and derivative thermogravimetric (DTG) curves of the untreated $M$. hypoleuca pulp and NFC are shown in Fig. 6.

As can be seen in Fig. 6(a), the initial weight loss of both cellulose samples began at around lower $100{ }^{\circ} \mathrm{C}$ owing to the evaporation of the water molecules in the cellulose (Pacheco et al. 2018). The weight losses of the untreated pulp and NFC at this transition were approximately 10 and 5\%, respectively. The lower weight loss obtained from the NFC might be because some of the hydroxyl groups $(-\mathrm{OH})$ on the NFC surfaces were converted to carbonyl groups $(\mathrm{C}=\mathrm{O})$ through esterification and the ester groups minimized the hydrophilic properties of the cellulose. The second thermal decomposition began at $220^{\circ} \mathrm{C}$ for the NFC and $250{ }^{\circ} \mathrm{C}$ for the untreated pulp. The final decomposition occurred at 280 and $365^{\circ} \mathrm{C}$ for the NFC and the untreated pulp, respectively (Fig. 6(b)). The differentiation of the thermal stability of the cellulosic materials has been reported to be influenced by the presence of the hemicellulose and lignin as the non-cellulosic components (Zhao et al. 2013). At $800{ }^{\circ} \mathrm{C}$, the weight loss of the NFC was $81 \%$, while the weight loss of the pulp was $87 \%$. The presence of the non-cellulosic component could protect the cellulosic material from heat effects. The decomposition (pyrolysis) process is influenced by the release of hydrogen and oxygen molecules from water through the process of dehydration, the decarbonylation process into monoxide, and the decarboxylation into carbon dioxide. 


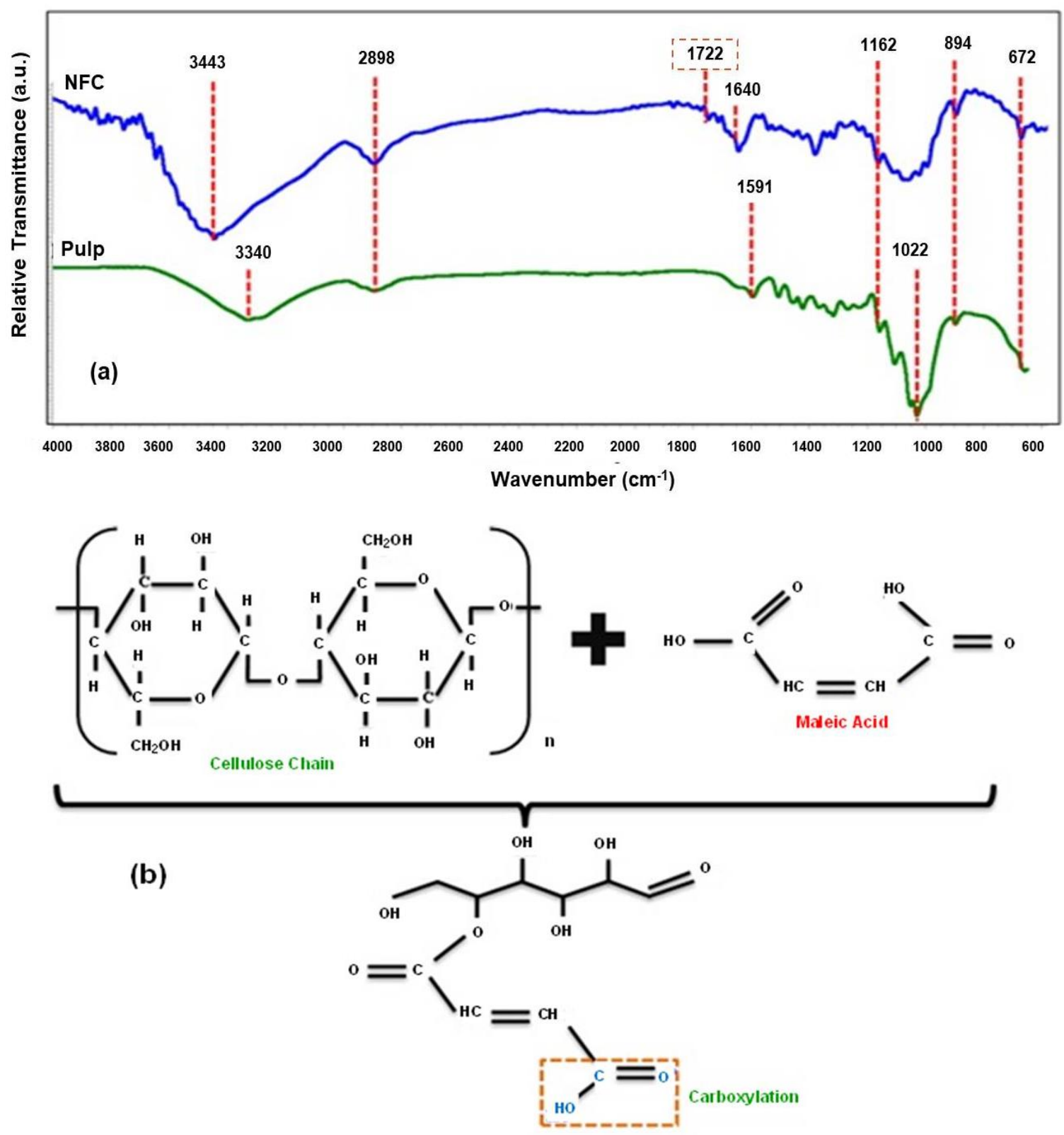

Fig. 5. (a) Fourier-transform infrared (FTIR) spectra of the untreated M. hypoleuca pulp and NFC and (b) esterification process induced by the $\mathrm{C}_{4} \mathrm{H}_{4} \mathrm{O}_{4}$

The NFC made from the $M$. hypoleuca pulp with $\mathrm{C}_{4} \mathrm{H}_{4} \mathrm{O}_{4}$ treatment decomposed at a lower temperature in comparison with pulp. This indicated the NFC produced by the esterification treatment had lower thermal stability. This may because of the disruption of hydrogen bonding by the carboxyl groups $(-\mathrm{COOH})$ at the $\mathrm{C} 6$ of the cellulose (Sharma and Varma 2014a) associated with the reduction in the molecular weight by defibrillation (Sharma and Varma 2014b). Moreover, the presence of the carboxyl groups would act as the catalyst for the decomposition (Chen et al. 2016), and the breadth of the higher surface area of the NFC would easily transfer the heat to each other (Bian et al. 2017a). Even though the NFC was produced by this treatment had lower thermal stability, the esterified NFC could be applied for nanocomposite applications (Ahuja et al. 2020). 

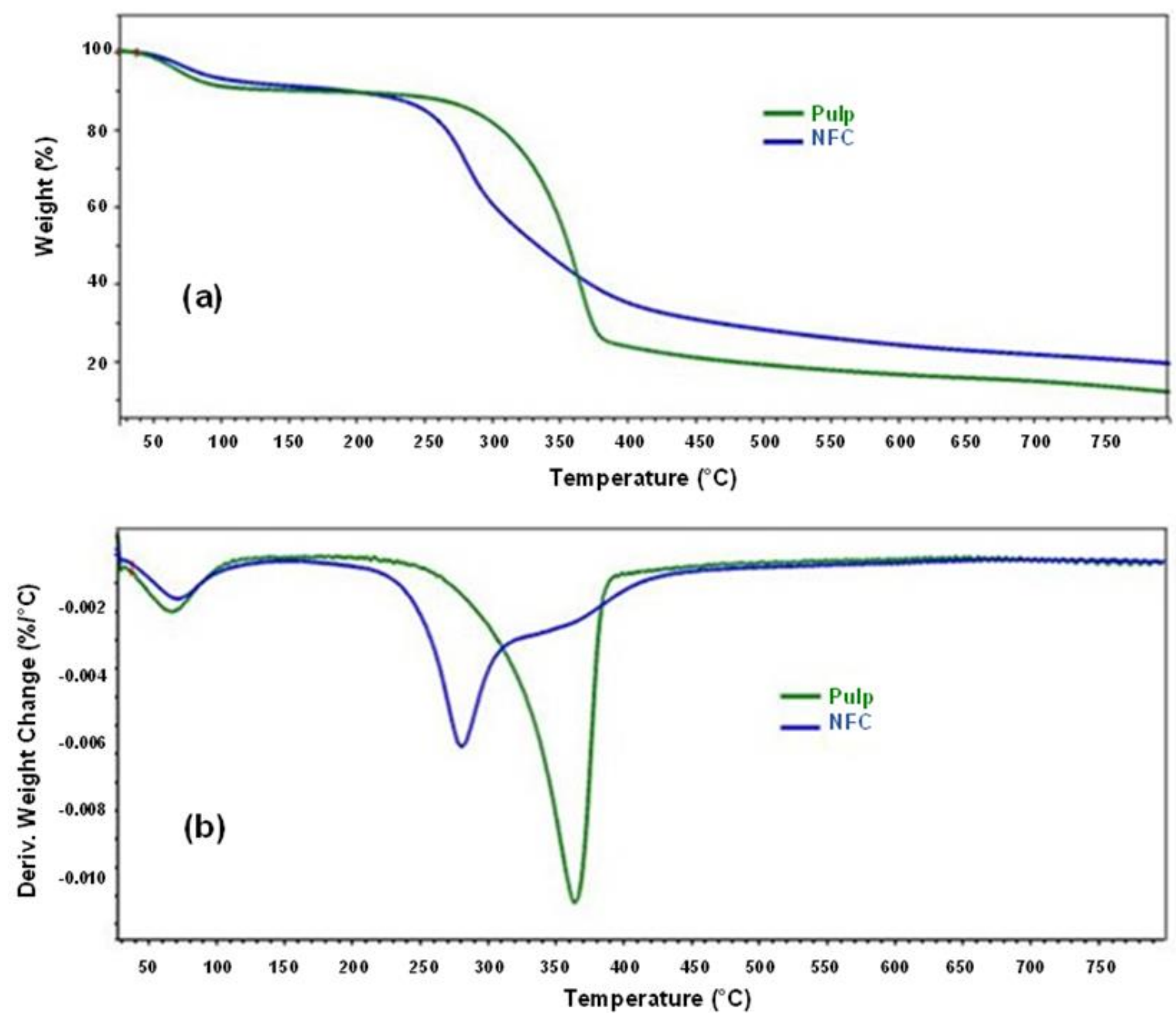

Fig. 6. (a) Thermogravimetric analysis (TGA) and (b) derivative thermogravimetric (DTG) curves of the untreated $M$. hypoleuca pulp and NFC

\section{CONCLUSIONS}

1. The isolation of nanofibrillated cellulose (NFC) from the M. hypoleuca wood species was successfully carried through a combination of chemical treatment (based on dicarboxylic acid) and mechanical treatment.

2. The NFC obtained had an average diameter of $43.0 \pm 8.6 \mathrm{~nm}$, a higher degree of crystallinity, and lower thermal stability compared to the NFC prepared from other wood species.

3. The Fourier transform infrared (FTIR) results showed that the NFC contained hemicellulose and lignin, and the cellulose structure was changed from type I to type II.

4. Based on the properties of the NFC prepared in this study, the Macaranga tree could be a suitable alternative source of lignocellulosic materials to produce NFC.

5. NFC prepared in this work would be useful for transparent flexible substrates, coatings, and composite materials. 


\section{ACKNOWLEDGMENTS}

This research was funded by Thailand Science Research and Innovation MidCareer Research Grant 2020 from the National Research Council of Thailand (Grant No. RSA6180085). The Research and Development of Forest Fiber Technology Institute, the Ministry of Environment and Forestry of the Republic of Indonesia also supported this work by supplying the raw material (M. hypoleuca pulp). The authors wish to thank the Department of Chemistry (Faculty of Science), Department of Tool and Materials Engineering (Faculty of Engineering), the Department of Production Engineering (Faculty of Engineering), and the Laboratory of Integrative Biorefinery (the Joint Graduate School of Energy and Environment), King Mongkut's University of Technology Thonburi, for providing the characterization instruments. An author (ES) would like to acknowledge the Petchra Pra Jom Klao Master Scholarship of King Mongkut's University of Technology Thonburi for the academic and financial support and Asst. Prof. Manisara Phiriyawirut and Asst. Prof. Sutatch Ratanaphan for the experimental suggestions.

\section{REFERENCES CITED}

Ahuja, D., Kumar, L., and Kaushik, A. (2020). “Thermal stability of starch bionanocomposites films: Exploring the role of esterified cellulose nanofibers isolated from crop residue," Carbohydrate Polymers 255(18), article ID 117466. DOI: 10.1016/j.carbpol.2020.117466

Bian, H., Chen, L., Dai, H., and Zhu, J. Y. (2017a). "Effect of fiber drying on properties of lignin containing cellulose nanocrystals and nanofibrils produced through maleic acid hydrolysis," Cellulose 24(10), 4205-4216. DOI: 10.1007/s10570-017-1430-7

Bian, H., Chen, L., Dai, H., and Zhu, J. Y. (2017b). "Integrated production of lignin containing cellulose nanocrystals (LCNC) and nanofibrils (LCNF) using an easily recyclable di-carboxylic acid," Carbohydrate Polymers 167, 167-176. DOI: 10.1016/j.carbpol.2017.03.050

Biswas, S. K., Tanpichai, S., Witayakran, S., Yang, X., Shams, I., and Yano, H. (2019). "Thermally superstable cellulosic-nanorod-reinforced transparent substrates featuring microscale surface patterns," ACS Nano 13(2), 2015-2023. DOI: 10.1021/acsnano.8b08477

Chen, W., Yu, H., Liu, Y., Chen, P., Zhang, M., and Hai, Y. (2011a). "Individualization of cellulose nanofibers from wood using high-intensity ultrasonication combined with chemical pretreatments," Carbohydrate Polymers 83(4), 1804-1811. DOI: 10.1016/j.carbpol.2010.10.040

Chen, W., Yu, H., Liu, Y., Hai, Y., Zhang, M., and Chen, P. (2011b). "Isolation and characterization of cellulose nanofibers from four plant cellulose fibers using a chemical-ultrasonic process," Cellulose 18(2), 433-442. DOI: 10.1007/s10570-0119497-z

Chen, L., Zhu, J. Y., Baez, C., Kitin, P., and Elder, T. (2016). "Highly thermal-stable and functional cellulose nanocrystals and nanofibrils produced using fully recyclable organic acids," Green Chemistry 18(13), 3835-3843. DOI: 10.1039/C6GC00687F

Chen, Y., Geng, B., Ru, J., Tong, C., Liu, H., and Chen, J. (2017). "Comparative characteristics of TEMPO-oxidized cellulose nanofibers and resulting nanopapers from bamboo, softwood, and hardwood pulps," Cellulose 24(11), 4831-4844. DOI: 


\subsection{7/s10570-017-1478-4}

Ciolacu, D., Ciolacu, F., and Popa, V. I. (2011). "Amorphous cellulose - Structure and characterization," Cellulose Chemistry and Technology 45(01), 13-21.

Cruz, N., Bustos, C., Aguayo, M. G., Cloutier, A., and Castilo, R. (2018). "Impact of the chemical composition of Pinus radiata wood on its physical and mechanical properties following thermo-hygromechanical densification," BioResources 13(2), 2268-2282. DOI: 10.15376/biores.13.2.2268-2282

French, A. D. (2014). "Idealized powder diffraction patterns for cellulose polymorphs," Cellulose 21(2), 885-896. DOI: 10.1007/s10570-013-0030-4

Frianto, D., and Rinanda, R. (2015). "Sekubung tree (Macaranga hypoleuca) as alternative raw material for pulp," in: National Conference in Indonesian Wood Research Society (MAPEKI), Bandung, Indonesia, pp. 183-189.

Guo, J., Fang, W., Welle, A., Feng, W., Filpponen, I., Rojas, O. J., and Levkin, P. A. (2016). "Superhydrophobic and slippery lubricant-infused flexible transparent nanocellulose films by photoinduced thiol-ene functionalization," ACS Applied Materials \& Interfaces 8(49), 34115-34122. DOI: 10.1021/acsami.6b11741

Junaedi, A. (2018). "Growth performance of three native tree species for pulpwood plantation in drained peatland of Pelalawan District, Riau," Indonesian Journal of Forestry Research 5(2), 119-132. DOI: 10.20886/ijfr.2018.5.2.119-132

Kargarzadeh, H., Mariano, M., Huang, J., Lin, N., Ahmad, I., Dufresne, A., and Thomas, S. (2017). "Recent developments on nanocellulose reinforced polymer nanocomposites: A review," Polymer 132, 368-393. DOI: 10.1016/j.polymer.2017.09.043

Kargarzadeh, H., Huang, J., Lin, N., Ahmad, I., Mariano, M., Dufresne, A., Thomas, S., and Gałeski, A. (2018). "Recent developments in nanocellulose-based biodegradable polymers, thermoplastics, and porous nanocomposites," Progress in Polymer Science 87, 197-227. DOI: 10.1016/j.progpolymsci.2018.07.008

Khawas, P., and Deka, S. C. (2016). "Isolation and characterization of cellulose nanofibers from culinary banana peel using high-intensity ultrasonication combined with chemical treatment," Carbohydrate Polymers 137, 608-616. DOI:

10.1016/j.carbpol.2015.11.020

Koga, H., Saito, T., Kitaoka, T., Nogi, M., Suganuma, K., and Isogai, A. (2013). "Transparent, conductive, and printable composites consisting of TEMPO-oxidized nanocellulose and carbon nanotube," Biomacromolecules 14(4), 1160-1165. DOI: $10.1021 / \mathrm{bm} 400075 \mathrm{f}$

Lampela, M., Jauhiainen, J., Sarkkola, S., and Vasander, H. (2017). "Promising native tree species for reforestation of degraded tropical peatlands," Forest Ecology and Management 394, 52-63. DOI: 10.1016/j.foreco.2016.12.004

Li, Y., Zhu, H., Xu, M., Zhuang, Z., Xu, M., and Dai, H. (2014). "High yield preparation method of thermally stable cellulose nanofibers," Bioresources 9(2), 1986-1997. DOI: 10.15376/biores.9.2.1986-1997

Meng, X., Wang, S., Gao, W., Han, W., and Lucia, L. A. (2020). “Thermal pyrolysis characteristics and kinetic analysis of nanofibrillated cellulose/graphene oxide composites," Bioresources 15(3), 4851-4865. DOI: 10.15376/biores.15.3.4851-4865

Nogi, M., Karakawa, M., Komoda, N., Yagyu, H., and Nge, T. T. (2015). "Transparent conductive nanofiber paper for foldable solar cells," Scientific Reports 5, 17254. DOI: 10.1038/srep17254

Oh, S. Y., Yoo, D. I., Shin, Y., Kim, H. C., Kim, H. Y., Chung, Y. S., Park, W. H., and 
Youk, J. H. (2005). "Crystalline structure analysis of cellulose treated with sodium hydroxide and carbondioxide by means of X-ray diffraction and FTIR spectroscopy," Carbohydrate Research 340(15), 2376-2391. DOI: 10.1016/j.carres.2005.08.007

Pacheco, C. M., Bustos, C., Reyes, G., Aguayo, M. G., and Rojas, O. J. (2018). "Characterization of residue from Chilean blueberry bushes: A potential source of cellulose," Bioresources 13(4), 7345-7359. DOI: 10.15376/biores.13.4.7345-7359

Pelissari, F. M., Sobral, P. J. A., and Menegalli, F. C. (2014). "Isolation and characterization of cellulose nanofibers from banana peels," Cellulose 21(1), 417432. DOI: 10.1007/s10570-013-0138-6

Petroudy, S. R. D., Sheikhi, P., and Ghobadifar, P. (2017). "Sugarcane bagasse paper reinforced by cellulose nanofiber (CNF) and bleached softwood kraft (BSWK) pulp," Journal of Polymers and the Environment 25(2), 203-213. DOI: 10.1007/s10924-0160800-9

Phiriyawirut, M., and Maniaw, P. (2012). "Cellulose microfibril from banana peels as a nanoreinforcing fillers for zein films," Journal of Polymer Chemistry 2(2), 56-62. DOI: 10.4236/ojpchem.2012.22007

Poletto, M., Ornaghi, H. L., and Zattera, A. J. (2014). "Native cellulose: Structure, characterization and thermal properties," Materials 7(9), 6105-6119. DOI: 10.3390/ma7096105

Ratanaphan, S., Olmsted, D. L., Bulatov, V. V., Holm, E. A., Rollett, A. D., and Rohrer, G. S. (2015). "Grain boundary energies in body-centered cubic metals," Acta Materialia 88, 346-354. DOI: 10.1016/j.actamat.2015.01.069

Romàn-Dañobeytia, F. R., Huayllani, M., Michi, A., Ibarra, F., Loayza-Muro, R., Vàzquez, T., Rodrígues, L., and García, M. (2015). "Reforestration with four native species after abandoned gold mining in the Peruvian Amazon," Ecological Engineering 85, 39-46. DOI: 10.1016/j.ecoleng.2015.09.075

Segal, L., Creely, J. J., Martin, A. E., and Conrad, C. M. (1959). "An empirical method for estimating the degree of crystallinity of native cellulose using the X-ray diffractometer," Textile Research Journal 29(10), 786-794. DOI: 10.1177/004051755902901003

Sethi, J., Oksman, K., Illikainen, M., and Sirviö, J. A. (2018). "Sonication-assisted surface modification method to expedite the water removal from cellulose nanofibers for use in nanopapers and paper making," Carbohydrate Polymers 197, 92-99. DOI: 10.1016/j.carbpol.2018.05.072

Sharma, P. R., and Varma, A. J. (2014a). "Functionalized celluloses and their nanoparticles: Morphology, thermal properties, and solubility studies," Carbohydrate Polymers 104(1), 135-142. DOI: 10.1016/j.carbpol.2014.01.015

Sharma, P. R., and Varma, A. J. (2014b). "Thermal stability of cellulose and their nanoparticles: Effect of incremental increases in carboxyl and aldehyde groups," Carbohydrate Polymers 114, 339-343. DOI: 10.1016/j.carbpol.2014.08.032

Slik, J. W. F., and Van Welzen, P. C. (2001). "A phylogeny of Mallotus (Euphorbiaceae) based on morphology: Indications for a pioneer origin of Macaranga," Systematic Botany 26(4), 786-796. DOI: 10.1043/0363-6445-26.4.786

Takeuchi, R., Wahyudi, I., Aiso, H., Ishiguri, F., Istikowati, W. T., Ohkubo, T., Ohshima, J., Iizuka, K., and Yokota, S. (2016). "Wood properties related to pulp and paper quality in two Macaranga species naturally regenerated in secondary forests, Central Kalimantan, Indonesia,” Tropics 25(3), 107-115. DOI: 10.3759/tropics.MS15-23

Tanpichai, S., and Witayakran, S. (2016). "All-cellulose composites from pineapple leaf 
microfibers: Structural, thermal, and mechanical properties," Polymer Composites 39(3), 895-903. DOI: $10.1002 /$ pc.24015

Tanpichai, S., and Witayakran, S. (2017). "All-cellulose composite laminates prepared from pineapple leaf fibers treated with steam explosion and alkaline treatment," Journal of Reinforced Plastics and Composites 36(16), 1146-1155. DOI: 10.1177/0731684417704923

Tanpichai, S., Biswas, S. K., Witayakran, S., and Yano, H. (2019). "Water hyacinth: A sustainable lignin-poor cellulose source for the production of cellulose nanofibers," ACS Sustainable Chemistry \& Engineering 7(23), 18884-18893. DOI: 10.1021/acssuschemeng.9b04095

Tanpichai, S., Witayakran, S., and Boonmahitthisud, A. (2019). "Study on structural and thermal properties of cellulose microfibers isolated from pineapple leaves using steam explosion," Journal of Environmental Chemical Engineering 7(1), 102836. DOI: 10.1016/j.jece.2018.102836

Tanpichai, S., Witayakran, S., Srimarut, Y., Woraprayote, W., and Malila, Y. (2019). "Porosity, density and mechanical properties of the paper of steam exploded bamboo microfibers controlled by nanofibrillated cellulose," Journal of Materials Research and Technology 8(4), 3612-3622. DOI: 10.1016/j.jmrt.2019.05.024

Tanpichai, S., Biswas, S. K., Witayakran, S., and Yano, H. (2020). "Optically transparent tough nanocomposites with a hierarchical structure of cellulose nanofiber networks prepared by the Pickering emulsion method," Composites Part A: Applied Science and Manufacturing 132, 105811. DOI: 10.1016/j.compositesa.2020.105811

TAPPI T9 wd-75. (2015). "Holocellulose in wood," TAPPI Press, Atlanta, GA.

TAPPI T222 om-11. (2015). "Acid-insoluble lignin in wood and pulp,” TAPPI Press, Atlanta, GA.

TAPPI T280 wd-06. (2015). “Acetone extractives of wood and pulp,” TAPPI Press, Atlanta, GA.

Tibolla, H., Pelissari, F. M., Martins, J. T., Vicente, A. A., and Menegalli, F. C. (2018). "Cellulose nanofibers produced from banana peel by chemical and mechanical treatments: Characterization and cytotoxicity assessment," Food Hydrocolloids 75(1), 192-201. DOI: 10.1016/j.foodhyd.2017.08.027

Tonoli, G. H. D., Teixeira, E. M., Corrêa, A. C., Marconcini, J. M., Caixeta, L. A., Pereira-da-Silva, M. A., and Mattoso, L. H. C. (2012). "Cellulose micro/nanofibres from Eucalyptus kraft pulp: Preparation and properties," Carbohydrate Polymers 89, 80-88. DOI: 10.1016/j.carbpol.2012.02.052

Trache, D., Hussin, M. H., Haafiz, M. K., and Thakur, V. K. (2017). "Recent progress in cellulose nanocrystals: Sources and production,” Nanoscale 9(5), 1763-1786. DOI: 10.1039/C6NR09494E

Wang, H., Chen, C., Fang, L., Li, S., Chen, N., Pang, J., and Li, D. (2018). "Effect of delignification technique on the ease of fibrillation of cellulose II nanofibers from wood," Cellulose 25(12), 7003-7015. DOI: 10.1007/s10570-018-2054-2

Wang, Q., Zhu, J. Y., and Considine, J. M. (2013). "Strong and optically transparent films prepared using cellulosic solid residue recovered from cellulose nanocrystals production waste stream," ACS Applied Materials \& Interfaces 5(7), 2527-2534. DOI: $10.1021 / \mathrm{am} 302967 \mathrm{~m}$

Yamada, T., Watanabe, K., Okuda, T., Sugimoto, T., and Azlin, Y. N. (2016). "Growth and survival of trees planted in an oil palm plantation: Implications for restoration of biodiversity," Journal of Tropical Forest Science 28(1), 97-105. DOI: 


\section{$10.2307 / 43748083$}

Yue, D., and Qian, X. (2018). "Isolation and rheological characterization of cellulose nanofibrils (CNFs) from coir fibers in comparison to wood and cotton," Polymers 10(3), 320-331. DOI: 10.3390/polym10030320

Zhao, J., Zhang, W., Zhang, X., Zhang, X., Lu, C., and Deng, Y. (2013). "Extraction of cellulose nanofibrils from dry softwood pulp using high shear homogenization," Carbohydrate Polymers 97(2), 695-702. DOI: 10.1016/j.carbpol.2013.05.050

Article submitted: November 3, 2020; Peer review completed: December 20, 2020;

Revised version received and accepted: November 23, 2021; Published: December 13, 2021.

DOI: $10.15376 /$ biores.17.1.922-938 